\title{
Further Studies on the Ultrastructure of the Human Axillary Apocrine Sweat Glands
}

\author{
By \\ KAZUMASA KUROSUMI and UTAKo KUROSUMI \\ Department of Morphology, Institute of Endocrinology, \\ Gunma University, Maebashi, Gunma 371, Japan \\ -Received for Publication, September 1, 1981-
}

\begin{abstract}
Key words: Apocrine sweat gland, Ultrastructure, Methenamine silver method, Axillary region, Man.

Summary : Secretory cells of the human axillary apocrine sweat gland were studied with the transmission electron microscope. They contain several different kinds of granules. Small granules and vesicles about $150 \mathrm{~nm}$ in diameter are arranged immediately beneath the luminal surface membrane. These granules are extremely variable in electron density, from very dense granules to clear vesicles. Some of these vesicles are opened to the gland lumen, and are suggestive of exocytosis. Some balloon-like cytoplasmic projections contain these vesicles. Therefore, it seems that the apical granules and vesicles are secretory in nature, and are released into the lumen by either exocytosis or an apocrine mechanism. They are stained well with the methenamine silver method, and are probably formed in the Golgi apparatus. Large dense granules are accumulated in the supranuclear cytoplasm. They contain small dense particles and medium-sized vacuoles. It is not likely that apical secretory granules or vesicles are derived from these large dense granules or the vacuoles in them. Medium-sized cored vacuoles are probably the precursors of large dense granules. A complex of loosely aggregated granules and droplets is also observed, and is thought to belong to the true lysosomes. It is suggested that the Golgi apparatus or GERL may produce the apical secretory granules and cored vacuoles. Mitochondria may develop into large, less dense granules due to a strong accumulation of matrix substance. The significance of such enlargement of mitochondria cannot be known yet. Infoldings of basal plasma membrane are observed, and while some of them are true infoldings, most of them are intercellular interdigitations.
\end{abstract}

The ultrastructure of secretory cells of luman axillary apocrine sweat glands las been studied with electron micro;copes by many authors (Kurosumi et al., .959; Charles, 1959 ; Yamada, 1960 ; Hibbs, 962 ; Biempica and Montes, 1965; Munyer, 1965; Hashimoto et al., 1966; Bell, .974 ; Schaumburg-Lever and Lever, 1975). lowever, the mechanism of formation of presumptive secretory granules and the release of these granules into the gland lumen remain to be studied more. Results of electron microscopic studies of similar apocrine glands of the external auditory canal (Kawabata, 1964; Kurosumi and Kawabata, 1976) have been useful to extend the knowledge of ultrastructural mechanisms of secretion in the apocrine 
sweat glands of the human axillary skin. The difficulties in autoradiographic studies in vivo as well as in applying certain hazardous experimental procedures on the living human skin resulted in a considerable delay in understanding the cytophysiology of the human sweat glands as compared with the glands of other species. We obtained a piece of the skin from the axillary region of a normal healthy person, and studied the sample in detail using a transmission electron microscope, both on stained sections prepared by the usual methods and those prepared by histochemical staining with periodic acid methenamine silver for detection of polysaccharides and glycoproteins. The results of these studies should be helpful in understanding the secretion mechanism of human apocrine sweat glands.

\section{Materials and Methods}

Axillary skin of a young adult male individual was removed surgically for treatment of osmidrosis. The specimen was cut into small pieces about $1 \mathrm{~mm}^{3}$ and fixed for $2 \mathrm{hrs}$ with $2.5 \%$ glutaraldehyde adjusted to $\mathrm{pH} 7.2$ with $1 / 15 \mathrm{M}$ phosphate buffer and made isotonic with $2.75 \%$ sucrose, and then postfixed with $2 \%$ osmium tetroxide with the same buffer for about 2 hrs. After dehydration with an ascending series of increasing concentrations of ethanol, the specimens were embedded in a mixture of Epon and Araldite. Thin sections were cut on an MT-2B Porter-Blum ultramicrotome with a glass knife. The thin sections which adhered to the copper grids were stained with uranyl acetate and lead citrate. Some sections were mounted on gold grids and stained with silver methenamine after oxidation with periodic acid by the method of Rambourg (1967) for demonstration of polysaccharides and glycoproteins.
The specimens were observed with transmission electron microscopes, either Hitachi HU-700 or Siemens Elmiskop 101, under the acclerating potential of $100 \mathrm{kV}$ or $75 \mathrm{kV}$, respectively.

\section{Results}

The secretory portion of the apocrine sweat gland in the human axillary skin is a coiled tubule whose lumen is very wide. Its wall consists of two kinds of cells, that is the secretory (glandular) cell and the myoepithelial cell. The secretory epithelium of this gland is a simple columnar epithelium, and its constituent cells are usually tall. The spherical nucleus is situated at the basal half of the cell. It contains a prominent nucleolus (Fig. 1). The luminal surface is more or less convex and sparsely arranged short microvilli extend from this surface into the gland lumen. Most of the lateral surface is smooth and straight, but along its basal end complicated folds are made by interdigitation between the neighboring cells. Along the basal or outer surface of the glandular epithelium, elongated myoepithelial cells are distributed in a direction parallel to the long axis of the gland tubule. Between the neighboring myoepithelial cells a narrow gap is formed, and filled with basal projections of secretory cells. The folding of plasma membrane are marked in this region, and therefore the contour of the secretory cell becomes extremely complicated in the area between myoepithelial cells. Most of the foldings of basal surface membranes of the secretory cells are formed by interdigitations between adjacent secretory cells, but some cytoplasmic projections may fold upon the surface of the same cell. Therefore, the plasma membrane may form a certain number of simple true infoldings along with the interdigitations (arrows in Fig. 2). A re- 
latively thick basal lamina (basement membrane) commonly invests both the myoepithelial cells and fold-bearing basal projections of the secretory cells.

The secretory cells contain several kinds of granules: the smallest type of granules are mainly distributed along the apical surface of the cell. They are about $100-200(150 \pm 30) \mathrm{nm}$ in diameter and each granule is covered with a limiting membrane. The internal substance of such small apical granules may vary remarkably in electron density (Figs. 3, 4). Some are quite opaque, while others are waterlike clear. The latter structures may be called vesicles rather than granules. Granules of various densities are observed between these two extremes, and they are probably transitional from dense granules to clear vesicles. Furthermore, there are numerous pits on the apical surface. Their sizes are almost the same as those of vesicles and granules, therefore the vesicles or granules may be opened to the gland lumen, and the internal substance may be poured out (Figs. $5,6,7)$. This phenomenon is the most frequently occurring mechanism of secretion release of the gland cells and corresponds to the so-called exocytosis.

Besides microvilli which have uniform width, much wider and stubby projections are occasionally observed (Fig. 7). Sometimes baloon-like projections may occur (Fig. 8). In the latter case, small vesicles which are similar in size to the apical secretory vesicles are arranged along the inner surface of the plasma membrane covering the projection. Some vesicles are not attached to the surface, but are situated centrally in the cytoplasm of the projection. If such a baloon-like projection is pinched off, the vesicles contained may be extruded into the gland lumen along with a part of the cytoplasmic matrix. This may be another mechanism of secretion discharge, and corresponds to the so-called apocrine secretion. As above mentioned, the small apical granules and vesicles may be extruded into the lumen by either exocytosis or apocrine mechanism. Therefore, these granules and vesicles are true secretory granules.

The second type of granules are very large and extremely dense granules. They measure about $0.8-1.0 \mu \mathrm{m}$ in diameter (Figs. 9, 10). Most of these dense granules are almost regularly round, but an additional type of dense granule is very rough and heterogeneous and contains small medium-dense granules and relatively clear droplets or vacuoles (Fig. 11). The former granules also contain clear vacuoles, some of which are situated along the periphery of the granules, as if they might be shed off from the large dense granules (Figs. 9, 10) (Kurosumi and Kawabata, 1976), but this possibility has not been clearly proven in electron micrographs studied in the present research. These first type dense granules are mostly homogeneous in appearance but they contain small dense particles of three different sizes (Figs. 9, 10), namely the largest is about $140 \mathrm{~A}$ in diameter, the middle is about $75 \mathrm{~A}$, while the smallest is about $50 \mathrm{~A}$. These particles are not distributed evenly in the granule, and therefore various patterns are made up in the granules. Sometimes these particles make a pattern like a skein of filaments, but true filamentous components could not be observed in the granules (Figs. 9, 10). Though high magnification views were repeatedly examined, neither particles nor filaments were found in the secretory granules arranged just beneath the apical plasma membrane (Fig. 3).

The second type of large dense granules are quite heterogeneous and looks like a complex of many small granules and droplets (Fig. 11). The matrix of this type of granule is slightly lower in density than that of the former granules. 
The first type dense granule corresponds to the Type I granule of Bell (1974), while the latter corresponds to her Type II granules. Type III granules of Bell are also found. They are medium-sized cored vacuoles (Fig. 12), whose diameters are variable from $170 \mathrm{~nm}$ to $550 \mathrm{~nm}$. Each vacuole is limited by a single membrane and contains less or medium dense substance, and a dark spot (core) is always seen in the vacuole. Such a core is usually eccentrically situated and its outline is not clear but fades away gradually into the less dense matrix surrounding the core. Such cored vacuoles are seen in various parts of the cytoplasm, but there is a tendency for small ones to be most often seen in the basal region of the cell, and relatively large vacuoles are often mixed up with large dense granules mostly distributed in the supranuclear or subapical part of the cell.

The last type of the granule in the apocrine gland cells is a large round granule of relatively low electron density (Fig. 12). Some of them reach up to an enormous size of about $3 \mu \mathrm{m}$ in diameter. They appear in the supranuclear and perinuclear region. They are surrounded with distinct double membranes and frequently contain arch-shaped double membranes, looking like cristae of mitochondria. As smaller ones of this type of granule are transitional to the oridinary mitochondria, these less dense granules are considered to be enlarged mitochondria due to an accumulation of a large amount of matrix substance. Such huge mitochondria are very unique and characteristic in the secretory cells of human apocrine sweat glands both in the axillary region (Kurosumi et al., 1959) and in the external auditory canal (Kawabata, 1964; Kurosumi and Kawabata, 1976). However, the significance of such enlargement of mitochondria is unknown, and neither sign of extrusion of these granules into the lumen nor transition to the apical secretory granules can be found.

The secretory cells contain well developed endoplasmic reticulum (ER) which is in the form of either vesicles or flattened sacs (Fig. 12). The latter are often located near large mitochondria. A close observation of these parts of the cytoplasm revealed that the cisternae of ER are partly smooth and partly rough (Fig. 12). Free ribosomes are also abundant, but vesicular cisternae of smooth ER are unexpectedly numerous in the apical cytoplasm. Bundles of cytoplasmic filaments are randomly distributed.

A well developed Golgi apparatus is located in the cytoplasm just above the nucleus, and consists of a large number of clear vacuoles closely contacted to one another (Figs. 13, 14). These vacuoles are nothing but dilated cisternae of Golgi lamellae. Many small vesicles are scattered near the lamellae (Fig. 13). Most of these vesicles are coated. A straight long tubule or double membranes are observed in the Golgi area, and their outer surface is also coated. The morphological characteristics of these membranous structures suggested that they correspond to the rigid lamella (Claude, 1970), which is part of GERL (Novikoff, 1964; Novikoff et al., 1977) (Fig. 14). A number of small dense granules about $150 \mathrm{~nm}$ in diameter are scattered in the Golgi region. They are larger than ordinary coated vesicles (Figs. 13, 14). The size and form of these small dense granules are comparable with the secretory apical granules and vesicles found just beneath the apical surface membrane.

Periodic acid methenamine silver staining is specific to glycoprotein and polysaccharide. The apical vesicles and granules are well stained. No vesicles negative to the staining were observed (Fig. 15). The large dense granules in the supranuclear cytoplasm are also 
positive to silver methenamine, but clear vacuoles in these granules are left unstained (Figs. 16, 17, 18). In the Golgi area small granules well stained with methenamine silver, having a similar size to the apical secretory granules are observed (Fig. 16). On the inner aspect of Golgi lamellae there are some elongate profiles enclosing material stainable with methenamine silver (Fig. 18). They are probably GERL but not Golgi lamellae, and it is suggested that sugar moieties in the materials of either apical secretory granules or subapical large dense granules might be synthesized in the GERL.

\section{Discussion}

Light microscopy and early electron microscopy revealed only large granules in the cytoplasm of secretory cells of the human apocrine sweat glands. In the axillary glands, Kurosumi et al. (1959) described dark and light secretory granules, and on the other hand, Charles (1959) called them rough and smooth secretory granules, respectively. Both of these study groups, however, could not observe small secretory granules and vesicles along the luminal cell surface. The formation of dark granules from cored vacuoles was suggested in our earliest report (Kurosumi et al., 1959). In that paper, we advocated that the homogeneous dark granules might change to dark granules of heterogeneous content, and finally the secretory substance might be diffused away in the apical cytoplasm, which in turn might be extruded by a pinching off mechanism, that is, the apocrine secretion. This idea was later supported by Hashimoto et al. (1966).

Another type of secretory granule, that is light granule was suggested to be derived from mitochondria by Kurosumi et al. (1959), but Charles (1959) denied the possibility that smooth granules might arise from mitochondria. At first we conjectured that light granules of enormous size might be secreted into the lumen, but this possibility was negated by Hibbs (1962), Yasuda et al. (1962), Kawabata (1964) and also Kurosumi and Kawabata (1976).

Small secretory granules or vesicles situated immediately beneath the apical cell membrane were first described by Yamada (1960). He thought that large dense granules might give rise to the apical small granules. This idea was later supported by Kawabata (1964) as well as Kurosumi and Kawabata (1976), and hence we called the large dark granules prosecretory granules in that paper. Hibbs (1962) thought the large granules were secretory in nature. $\mathrm{He}$ also described the presence of small vesicles and granules distributed along the apical surface. Though he denied the apocrine secretory mechanism, he wrote that the secretion discharge might be "droplet secretion", which was not reconciled with our classification of extrusion mechanisms (Kurosumi, 1961).

Biempica and Montes (1965) as well as Hashimoto et al. (1966) demonstrated acid phosphatase (AcPase) activity on the large dense granules, and considered that the granules were nothing but lysosomes. Biempica and Montes (1965) showed no possible correlation between the large dense granules and small apical vesicles or granules, though they considered that apical vesicles might undergo exocytosis. Kurosumi and Kawabata (1976) also demonstrated AcPase activity in the large dense granules. Furthermore, in the apical vesicles and also in a part of the gland lumen near the apical surface of secretory cells reaction products for AcPase activity were observed. Therefore, we thought that the lysosomal enzymes might be transferred from the large dense granules to the apical vesicles as a result of budding of clear vacuoles, and finally extruded into 
the gland lumen by exocytosis of apical vesicles.

On the other hand, Munger (1965) thought that the dark granules might contain keratin, but Bell (1965) negated this idea. She classified the dark granules into three types. Her following notion is very akin to that of ours: that is, Type III granules of Bell which correspond to the cored vacuoles in our present description might transform into the Type I granules (homogeneous regular round granules). She did not refer to the small apical granules or vesicles. However, Munger (1965) wrote that the apical vesicles might arise from the Golgi apparatus and be released into the lumen by exocytosis. This opinion was supported by Schaumburg-Lever and Lever (1975) and also by our present observations; that is, the small secretory granules may originate from the Golgi apparatus or GERL, migrate to the apical end of the secretory cell, where the electron density of the internal substance becomes reduced to form vesicles, which are finally released by exocytosis. Some of these secretory vesicles are clear and resemble the vacuolated portions of the large dense granules, but the former vesicles are always stained with methenamine silver, and the clear vacuoles in the dense granules are negative, though the dense part of the large granules reacts positively. This may suggest that the large dense granules are lysosomes but neither secretory nor prosecretory. The reason why such large lysosomes are formed in the human apocrine sweat gland cells has not yet been explained. The idea that cored vacuoles may give rise to the large dense granules has not been changed since our first report (Kurosumi et al., 1959).

It has been long debated whether or not the apocrine secretion or decapitation may naturally occur in the apocrine sweat glands. Some authors such as Yamada
(1960), Hibbs (1962), Biempica and Montes (1965), Bell (1974) and Munger (1965) argued that the apocrine secretion suggested by cytoplasmic ballooning might be an artefact which occurs during specimen preparation. However, the senior author of this paper and his coworkers (Kurosumi et al., 1959; Kawabata, 1964; Kurosumi and Kawabata, 1976) repeatedly demonstrated the cytoplasmic projections extending into the lumen suggestive of apocrine secretion. Especially in the last paper (Kurosumi and Kawabata, 1976), we observed luminal projections of cytoplasm by scanning electron microscopy as well as transmission electron microscopy. In the present research we observed again the stubby or balloon-like projections of the apical cytoplasm, some of which contained a number of small vesieles, suggestive of their being released by the apocrine mechanism. Hashimoto et al. (1966) and Schaumburg-Lever and Lever (1975) also argued that the apocrine mechanism is really active in the apocrine sweat glands in the human axilla. Among animal sweat glands such as the rabbit (Kurosumi et al., 1961), horse (Kurosumi et al., 1963; Sørensen and Prasad, 1973) and lemur (Kneeland, 1966), the apocrine mechanism of secretion release has been repeatedly observed. In the rat mammary glands, Bargmann and his associates $(1959,1961)$ denied this mechanism, but the present author and his colleagues (Kurosumi et al. 1968) showed the events occurring in the lactating mammary glands of the rat and demonstrated the apocrine secretion; not only fat droplets but also casein particles are discharged by the apocrine mechanism along with exocytosis. Like the casein particles in the mammary cells, glycoprotein secreretory granules and vesicles arranged along the apical surface of the secretory cell in the human axillary glands may be released by two ways, that is apocrine secretion and exocytosis. Schaum- 
burg-Lever and Lever (1975) argued for three mechanisms : holocrine, apocrine and exocytosis, but the holocrine secretion may be doubted since it might well be based on artefacts.

The folding of the basal plasma membrane of sweat gland cells was first reported by Takahashi (1957) in the human apocrine sweat glands. Then Kurosumi and Kitamura (1958) found it in the pig's carpal organ (apocrine sweat gland). Successively we found the basal folded membranes in the human apocrine (Kurosumi et al. 1959) and eccrine sweat glands (Kurosumi et al., 1960).

These structures were known to develop in some epithelial cells which function in water transport such as the renal tubules (Rhodin, 1958) and the striated duct of the salivary glands (Tamarin and Sreebny, 1965). They were thought to be interdigitations between the adjacent cells, but true infoldings are clearly demonstrated in the present observation. A row of microvesicles continuous with the infolded membranes at the cell base reported by Kurosumi et al. (1959) and by Munger (1965) are considered to be an artefact occurring fixation, especially with osmium tetroxide alone, because the specimens with better fixation by glutaraldehyde and osmium tetroxide did not show such a vesiculation of folded basal plasma membranes.

\section{Acknowledgements}

The authors wish to express their appreciation to Dr. N. Baba, the Second Department of Surgery, Gunma University School of Medicine and to Dr. K. Inoue of the authors' laboratory for their collaboration in specimen preparation. We thank Miss Tosaka of our laboratory for her assistance in staining the specimens by silver methenamine. The authors are obliged to Dr. E. G. Rennels, Department of Anatomy, The University of Texas Health Science Center at San Antonio for his kindness in allowing us to use an electron microscope and related facilities in his laboratory during the authors' stay in San Antonio and his critical reading of the manuscript and his useful suggestions.

\section{References}

1) Bargmann, W., Fleischhauer, K. und Knoop, A.: Über die Morphologie der Milchsekretion. II. Zugleich eine Kritik am Schema der Sekretionsmorphologie. Z. Zellforsch., 53: 545-568, 1961.

2) Bargmann, W. und Knoop, A.: Über die Morphologie der Milchsekretion. Licht- und elektronenmikroskopische Studien an der Milchdrüse der Ratte. $Z$. Zellforsch., 49: 344-388, 1959,

3) Bell, M.: The ultrastructure of human axillary apocrine glands after epinephrine injection. J. Invest. Derm., 63: 147-159, 1974.

4) Biempica, L. and Montes, L. F.: Secretory epithelium of the large axillary sweat glands. A cytochemical and electron microscopic study. Am. J. Anat., 117: 47-72, 1965.

5) Charles, A.: An electron microscopic study of the human axillary apocrine gland. J. Anat., 93: 226-232, 1959.

6) Hashimoto, K., Gross, B.G. and Lever, W.F.: Electron microscopic study of apocrine secretion. J. Invest. Derm., 46 : 378-390, 1966.

7) Hibbs, R.G.: Electron microscopy of human apocrine sweat glands. J. Invest. Derm., $38:$ 77-84, 1962.

8) Kawabata, I.: Electron microscopy of human ceruminous gland. Arch. Hist. Jap., 25 : 165-187, 1964.

9) Kneeland, J.E.: Fine structure of the sweat glands of the antebrachial organ of Lemur catta. Z. Zellforsch., 73: 521533, 1966.

10) Kurosumi, K.: Electron microscopic analysis of the secretion mechanism. Int. Rev. Cytol., 11: 1-124, 1961.

11) Kurosumi, K. and Kawabata, I.: Trans- 
mission and scanning electron microscopy of the human ceruminous apocrine gland. I. Secretory glandular cells. Arch. Hist. Jap., 39 : 207-229, 1976.

12) Kurosumi, K. and Kitamura, T.: Occurrence of foldings of plasma membrane ( $\beta$-cytomembrane) in cells of pig's carpal organ as revealed by electron microscopy. Nature, 181, 489, 1958.

13) Kurosumi, K., Kitamura, T. and Iijima, T.: Electron microscope studies on the human axillary apocrine sweat glands. Arch. Hist. Jap., 16 : 523-566, 1959.

14) Kurosumi, K., Kitamura, T. and Kano, K.: Electron microscopy of the human eccrine sweat gland from an agsed individual. Arch. Hist. Jap., 20: 253269, 1960.

15) Kurosumi, K., Kobayashi, Y. and Baba, N.: The fine structure of mammary glands of lactating rats, with special reference to the apocrine secretion. Exp. Cell Res., 50 : 177-192, 1968.

16) Kurosumi, K., Matsuzawa, T. and Saito, F.: Electron microscopic observations on the sweat glands of the horse. Arch. Histol. Jap., 23 : 295-310, 1963.

17) Kurosumi, K., Yamagishi, M. and Sekine, M.: Mitochondrial deformation and apocrine secretory mechanism in the rabbit submandibular organ as revealed by electron microscopy. Z. Zellforsch., 55, 297-312, 1961.

18) Munger, B.L.: The cytology of apocrine sweat glands. II. Human. Z. Zellforsch., 68 : 837-851, 1965.

19) Novikoff, A.B.: GERL, its form and function in neurons of rat spinal ganglia. Biol. Bull., 127 : 358A, 1964.

20) Novikoff, A. B., Mori, M., Quintana, N. and Yam, A.: Studies of the secretory process in the mammalian exocrine pancreas. J. Cell Biol., 75 : 148-165, 1977.

21) Rambourg, A.: An improved silver methenamine technique for the detection of periodic acid-reactive complex carbohydrates with the electron microscope. J. Histochem. Cythchem., 15: 409-412, 1967.

22) Rhodin, J.: Anatomy of kidney tubules. Int. Rev. Cytol., 7 : 485-534, 1958.

23) Schaumburg-Lever, G. and Lever, W. F. : Secretion from human apocrine glands: An electron microscopic study. J. Invest. Derm., 64 : 38-41, 1975.

24) S $\phi$ rensen, V. W. and Prasad, G.: On the fine structure of horse sweat glands. Z. Anat. Entw.-Gesch., 139 : 173-183, 1973.

25) Takahashi, N.: Electron microscopic studies on the ectodermal secretory glands in man. I. The fine structure of the apocrine sweat gland, with special reference to the myoepithelium. Bull. Tokyo Med. Dent. Univ., 4: 259-269, 1957.

26) Tamarin, A. and Sreebny, L. M.: The rat submaxillary salivary gland. A correlative study by light and electron microscopy. J. Morph., 117: 295-352, 1965.

27) Yamada, H.: Electron microscopic observations on the secretory process of the axillary apocrine glands. Acta Path. Jap., 10 : 173-187, 1960.

28) Yasuda, K., Ellis, R. A. and Montagna, W.: The fine structural relationship between mitochondria and light granules in the human apocrine sweat glands. Okajimas Fol. Anat. Jpn., 38: 455-483, 1962. 


\section{PLATES}




\section{Explanation of Figures}

\section{Plate I}

Fig. 1. Columnar secretory cells and underlying myoepithelial cells (ME) of the human axillary apocrine sweat gland. The nucleus $(\mathrm{N})$ of the secretory cell is situated at a position slightly basal from the center of the cell. In the supranuclear region, a number of enorm. ous mitochondria (M) and a few large dense granules (D) are observed. Luminal cell surface is provided with microvilli, and the most apical part of the cell contains neither mitochondria nor large granules, but small vesicles and granules (S) are scattered. Gaps between myoepithelial cells are filled with projections of secretory cells with ample foldings of cell membranes $(F) . \quad \times 6,600$. 
Plate I

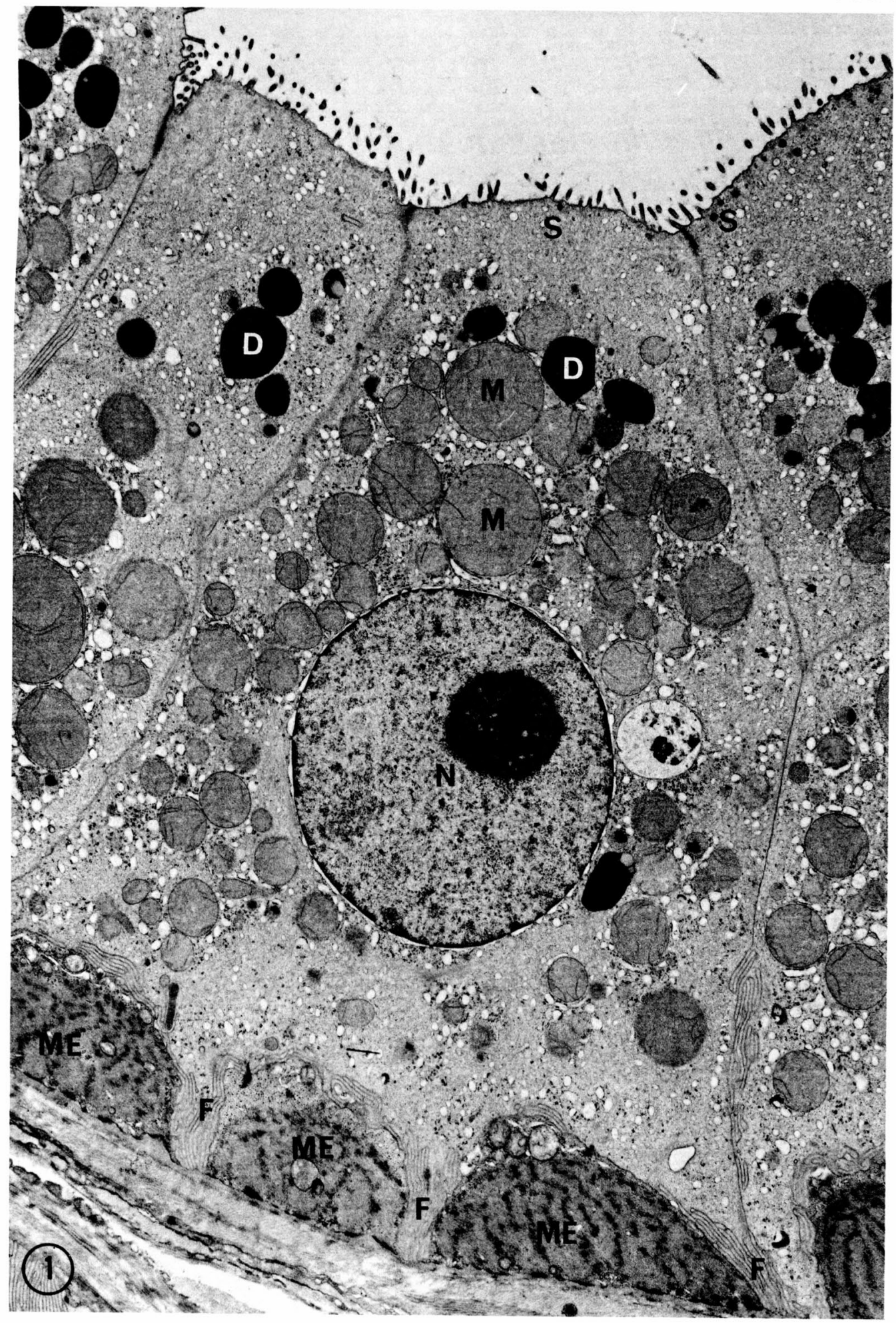

K. Kurosumi and U. Kurosumi 


\section{Plate II}

Fig. 2. Basal parts of secretory cell with complicated foldings of plasma membrane (F). Most of the foldings are formed by intercellular interdigitation, but true infoldings are also seen (arrows). ME: myoepithelial cell. $\times 44,000$.

Fig. 3. Apical part of a secretory cell containing many small secretory granules with relatively dense content $(\mathrm{S})$. Vesiculated cisternae of ER partly smooth and partly rough are present. $\times 44,000$.

Fig. 4. Apical parts of some secretory cells. A number of clear vesicles and medium-dense granules are arranged along the surface plasma membrane. Some of these vesicles are quite clear (arrow), as if they contained only water. $\times 44,000$.

Figs. 5 and 6 . Several pits on the surface of secretory cells are suggestive of exocytosis (arrows). $\times 44,000$. 
Plate II


K. Kurosumi and U. Kurosumi

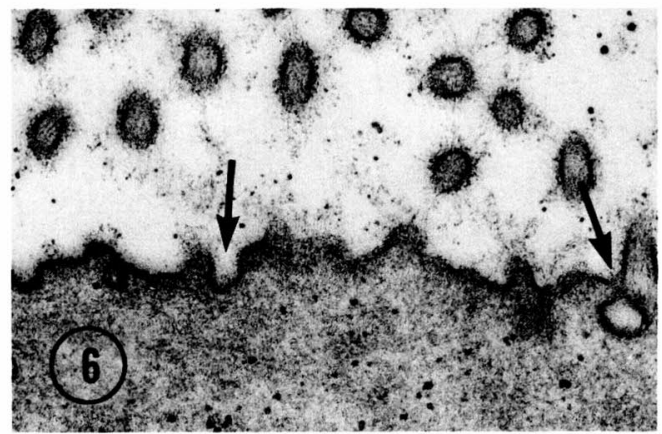




\section{Plate III}

Fig. 7. Apical surface of a secretory cell provided with microvilli, an exocytotic pit (arrow) and a stubby projection $(\mathrm{P})$ suggestive of apocrine secretion. $\times 51,000$.

Fig. 8. A balloon-like projection (P) on the apical surface of a secretory cell. Small secretory vesicles are arranged along the surface of the projection. $\times 50,000$.

Figs. 9 and 10. Large dense granules (D) found in the supranuclear cytoplasm of secretory cells. Clear vacuoles (V) are found mostly in the periphery of dense granules. The granules contain small particles of various sizes, distributed irregularly. ER indicates vesiculated cisternae partly smooth and partly rough. Fig. 9: $\times 50,000$, Fig. 10: $\times 65,000$. 

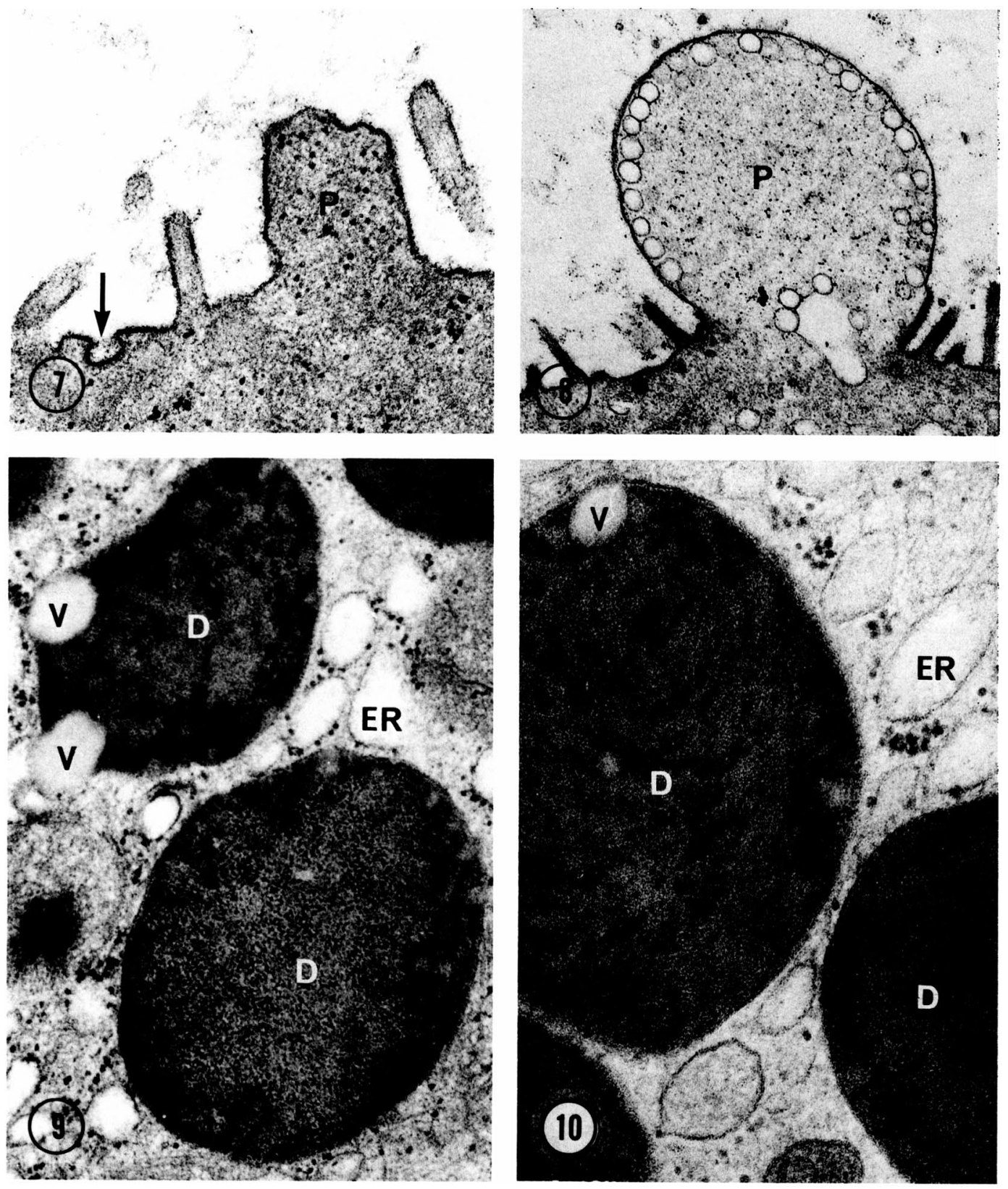

K. Kurosumi and U. Kurosumi 


\section{Plate IV}

Fig. 11. Apical part of a secretory cell showing many large granules accumulated in the supranuclear region. Regularly round dense granules (D1), irregular heterogeneous granules (D2) and light granules derived from mitochondria (M) are observed. $\times 10,000$.

Fig. 12. Supranuclear cytoplasm of a secretory cell. Large mitochondria (M), rough and smooth ER, cored vacuoles (CV) of different sizes and bundles of microfilaments (MF) are observed. $\times 32,000$.

Figs. 13 and 14. Golgi area of secretory cells. Slightly dilated cisternae of the Golgi lamellae (GL) are put together. A large number of Golgi vesicles (GV) are accumulated near the lamellae. A rigid lamella $(R)$ with a swollen tip is observed. Small dense granules found in the Golgi area (arrows) may be the precursors of apical secretory granules. Lysosomes (L) are also seen. Both $\times 41,000$. 

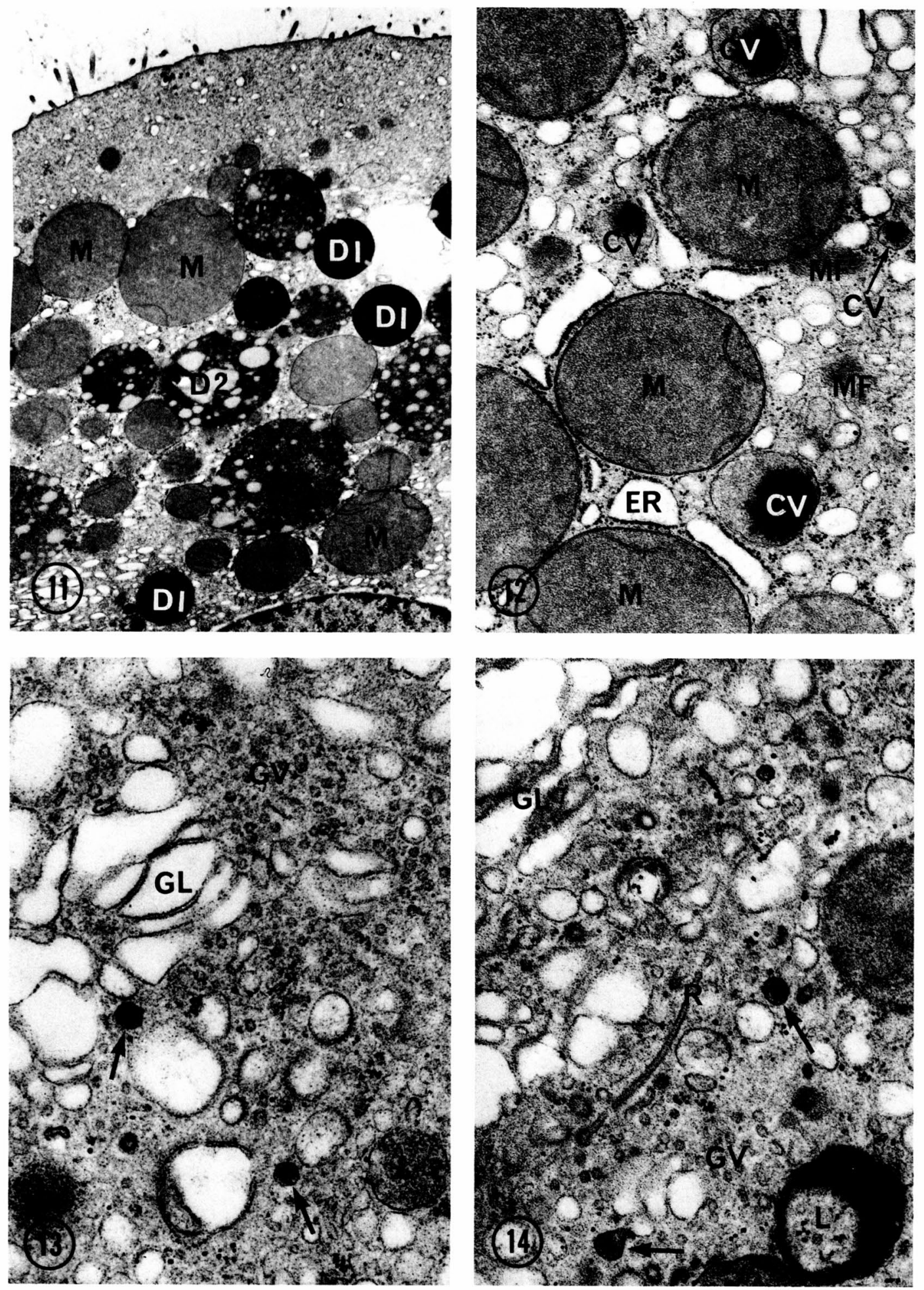

K. Kurosumi and U. Kurosumi 


\section{Plate V}

Figs. 15-18. Secretory cells of the human axillary apocrine sweat glands stained with periodic acid methenamine silver are shown. Polysaccharides and glycoproteins are stained black by this method.

Fig. 15. Apical zone of a secretory cell extending many microvilli into the gland lumen. Secretory granules and vesicles (S) are intensely stained with methenamine silver. $\times 18,000$.

Fig. 16. Apical and supranuclear regions of a secretory cell. Both small secretory granules (S) and large dense granules (D) are stained black. Within the Golgi area (G) some methenamine silver stained small granules are observed (arrows). They are similar in size to the apical secretory granules. $\times 12,000$.

Fig. 17. Supranuclear part of a secretory cell. There are many large dense granules (D), especially the central granule contains many unstained vacuoles. $\times 14,000$.

Fig. 18. Golgi apparatus $(G)$ of a secretory cell is illustrated. Elongated sacs at the inner aspect of Golgi lamellae, probably corresponding to rigid lamellae (arrows), contain darkstained substance, which may be accumulation of sugar-containing material either becoming small secretory granules or large dense granules (D). $\times 12,000$. 
Plate V
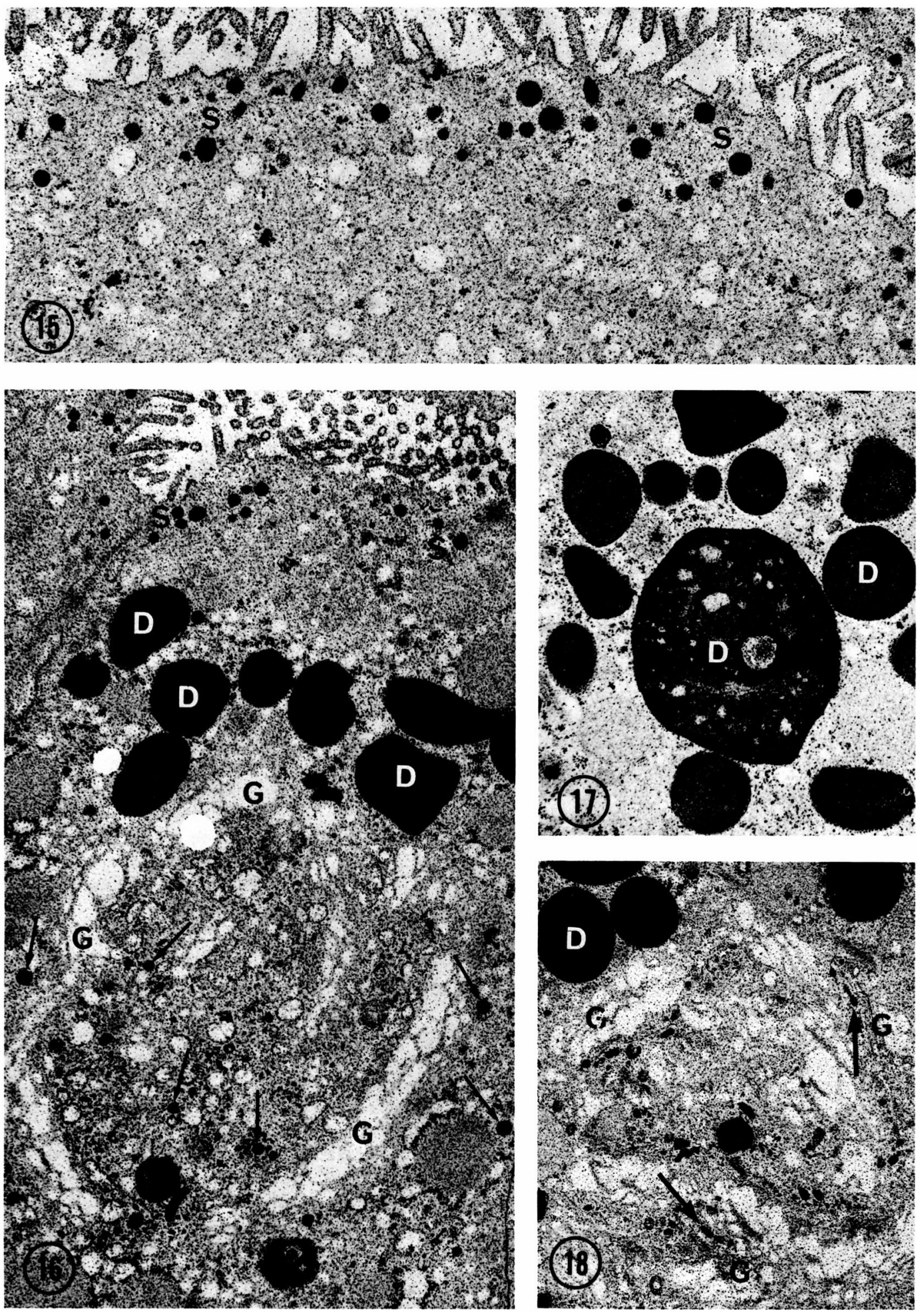

K. Kurosumi and U. Kurosumi 